\title{
Responses of sexually experienced and naive male rats to cues from receptive vs. nonreceptive females
}

\author{
MICHAEL R. LANDAUER, ROBERT E. WIESE, JR., and W. J. CARR \\ Beaver College, Glenside, Pennsylvania 19038
}

\begin{abstract}
In order to learn more about their reaction to the female sex attractant, 61 male Norway rats were given two-choice preference tests in which they reacted to cues from receptive vs. nonreceptive females. In the first experiment, 16 heterosexually experienced males showed a reliable preference $(p<.01)$ for receptive over nonreceptive anesthetized females, as did 15 naive males $(p<.02)$ which later proved to be copulators. Ten naive males which later proved to be noncopulators showed no reliable preference for either type of female. In the second experiment, 15 naive males which later proved to be copulators showed no reliable preference for the odors from receptive vs. nonreceptive females. From these experiments, we conclude that naive males which later prove to be sexually vigorous are attracted to the composite bodily cues from receptive females, and that this attraction is not mediated by olfactory cues alone.
\end{abstract}

Considerable evidence supports the view that, under certain conditions, male Norway rats prefer the odor from receptive females over that from nonreceptive females, suggesting that the former odor contains a sex attractant (Bronson, 1974; Carr, 1974). This attractant probably facilitates reproduction by enabling males by locate and focus their mating activities on females likely to produce young.

A number of investigators have explored the hormonal and experiential determinants of the preference by male rats for the receptive female odor. All agree that the preference is androgen dependent. Untreated prepuberal males and castrated adult males, with or without prior sex experience, show no reliable preference for either feminine odor (Carr, Loeb, \& Dissinger, 1965; Carr, Loeb, \& Wylie, 1966; Carr, Wylie, \& Loeb, 1970; LeMagnen, 1952; Pfaff \& Pfaffmann, 1969; Stern, 1970).

On the other hand, investigators disagree as to whether the preference for the odor from receptive females over that from nonreceptive females also requires prior heterosexual copulatory experience on the part of male rats. Some reported such a preference in naive males (LeMagnen, 1952; Pranzarone, 1968; Hitt, Phillips, \& Asato, Note 1), while others reported the preference in experienced males but not in naive males (Carr, 1974; Carr et al., 1965; Keesey, 1962; Lydell \& Doty, 1972; Stern, 1970). The dis-

This research was supported in part by U.S. Public Health Service Grants MH25456 and HD07043. We thank Lily Yee for technical assistance. Michael $\mathbf{R}$. Landauer is now at the Department of Biological Sciences, Barnard College, Columbia University, New York, New York 10027. Requests for reprints should be sent to W. J. Carr, Department of Psychology, Beaver College, Glenside, Pennsylvania 19038 agreement may stem from differences in testing technique or from differences in the strain or age of the animals tested.

\section{EXPERIMENT 1}

Using a modification of a technique developed earlier (Landauer, 1975; Landauer, Banks \& Carter, in press a; Landauer, Banks \& Carter, in press b), the present experiment was performed to determine whether heterosexually naive as well as experienced male rats respond differentially in a preference test during which they encounter two anesthetized females, one receptive and one nonreceptive. Moreover, we sought to determine whether the performance of the naive males during the preference test varies with their sexual vigor, assessed after the preference test was completed.

The present technique enabled the male subjects to use any or all bodily cues (e.g., olfactory, gustatory, tactile, or visual) which distinguish receptive from nonreceptive females. Since the males had direct access to the anesthetized females, the bodily cues were at maximum strength and could be used in combinations or as functional equivalents (Gibson, 1966, pp. 54-55). Further, by using anesthetized females, we could observe the males' reactions to these bodily cues, uninfluenced by differences in behavior exhibited by active (unanesthetized) receptive vs. nonreceptive females. The former court males as well as permit them to mount, but the latter neither court nor permit mounting (Barnett, 1975, p. 138; Larsson, 1956, p. 33). Should naive males prefer receptive over nonreceptive females when all the bodily cues are present and all the behavioral cues 
are absent, the way would be open for additional research aimed at identifying the bodily cue(s) mediating the preference.

\section{Method}

Subjects. Forty-one male rats (Rattus norvegicus) of the LongEvans strain (Perfection Breeders, Douglassville, Pa.) were tested at 10.5-12 months of age for their reactions to a pair of anesthetized females, one receptive and one nonreceptive. Except as noted below, the males were housed from the time of weaning in sexually segregated groups of $2-4$ in wire mesh cages, measuring $25 \times 41$ $\times 71 \mathrm{~cm}$. The floors were covered with pine wood shavings which were changed weekly and on the day before testing. The males were maintained in a temperature-controlled room $\left(23^{\circ} \mathrm{C}\right)$ on a 12:12 $\mathrm{h}$ light:dark cycle, the lights going off at $1100 \mathrm{~h}$. Charles River lab chow checkers and water were freely available.

Procedure and Apparatus. The $\mathbf{4 1}$ males were assigned randomly to one of two groups, one group $(n=16)$ receiving heterosexual copulatory experience prior to preference testing and the other $(n=25)$ remaining heterosexually naive until after preference testing. One week before preference testing, each of the 16 experienced males achieved at least one ejaculation with a receptive female during a $1-h$ training period conducted in the male's home cage.

Each male received a single 10-min preference test in its home cage, during which it encountered the two anesthetized females. Just before the test, the males living in a given home cage were transferred to a holding cage and the two anesthetized females were placed in the home cage at positions $10 \mathrm{~cm}$ to the left or right of the center of the cage, along its long axis. The females were placed on their backs, thereby exposing their anogenital regions.

When the females were in position, each male subject was returned individually to its home cage for $10 \mathrm{~min}$, during which an experimenter recorded the number of seconds the male spent investigating each female. A male was said to be investigating a female if the male's nose was within $1 \mathrm{~cm}$ of the female's body.

Several precautions were taken to eliminate possible artifacts from the testing procedure. First, a different pair of females was used for only one male's test on a given day of testing and at least 7 days passed before that pair was presented to another male. Second, the relative positions of the two types of female were counterbalanced across subjects to control for a possible position preference on the part of the male subjects. Third, the experimenter observing a given male did not know the hormonal state of either female. Fourth, the experimenters wore different gloves while handling receptive and nonreceptive females to prevent the mixing of these odors and to minimize human odors (McCall, Lester, \& Corter, 1969). Finally, all preference tests were conducted under dim light during the first $6 \mathrm{~h}$ of the dark phase of the light:dark cycle.

Among domestic male rats raised under standard laboratory conditions, $20 \%-40 \%$ fail consistently to copulate with receptive females (Pottier \& Baran, 1973; Whalen, 1964), and the performance of our heterosexually naive males in the preference test may have varied with the males' sexual vigor. Therefore, beginning
6-8 weeks after testing, these males were housed individually in wire mesh cages (Wahmann, LC-75/B), measuring $17 \times 25 \times$ $41 \mathrm{~cm}$, where they were tested for sexual vigor. Each male cohabited with a receptive female during three 18 -h tests, beginning 1,2 , and 7 days after isolation. The males were observed for the first $20 \mathrm{~min}$ of each test. Further, the tray beneath each cage was lined with paper which was checked for copulatory plugs at the end of each test. Males observed to ejaculate or produce plugs during one or more tests were designated as copulators, and 15 of the 25 males met this criterion.

The 40 females used in this experiment were of the same strain, but were 1 month older than the male subjects. They were maintained in the same manner as the males, except that they were gonadectomized when they were 6 months old. Receptive females received subcutaneous injections of $.01 \mathrm{mg}$ estradiol benzoate in $.1 \mathrm{cc}$ sesame oil $54 \mathrm{~h}$ before use, and of $.4 \mathrm{mg}$ progesterone in $.1 \mathrm{cc}$ sesame oil $6 \mathrm{~h}$ before use (Whalen, 1974). Nonreceptive females received the same amounts of sesame oil according to the same schedule, but without the ovarian hormones. Females were considered to be receptive only if they exhibited the lordotic reflex when stimulated manually. The females were anesthetized 30 min before testing via an IP injection of sodium pentobarbitol (Nembutal), at a dosage of $35 \mathrm{mg} / \mathrm{kg}$.

\section{Results and Discussion}

Table 1 summarizes the performance of the three groups of males during the 10-min preference test. The sexually experienced males exhibited a reliable preference for receptive over nonreceptive anesthetized females. Wilcoxon matched-pairs signedranks test, $T(16)=11, p<.01$, as did the naive males which later proved to be copulators, $T(15)$ $=18, \mathrm{p}<.02$. Eighty-eight percent $(14$ out of 16$)$ of the experienced males and $80 \%$ (12 out of 15 ) of the naive males (copulators) spent more time investigating receptive females than nonreceptive females. However, the naive males which later proved to be noncopulators showed no reliable preference for either type of female. Therefore, we conclude that the preference for the bodily cue(s) which distinguish receptive from nonreceptive females does not require prior heterosexual copulatory experience on the part of male Norway rats which later prove to be sexually vigorous. Additional research is required to determine whether their preference depends on some type of prior social experience other than copulation.

One might also consider differences among the three groups of male subjects in responsiveness to females, regardless of their ovarian hormonal condition; i.e., the between-group differences in the

Table 1

Responses of Males to Receptive and Nonreceptive Anesthetized Females During 10-Min Test

\begin{tabular}{lcccccc}
\hline & \multicolumn{4}{c}{ Investigation Time (Seconds) } \\
\cline { 2 - 6 } $\begin{array}{c}\text { Males' Mating } \\
\text { History }\end{array}$ & $\mathrm{N}$ & $\begin{array}{c}\text { Receptive } \\
\text { Female }\end{array}$ & $\begin{array}{c}\text { Nonreceptive } \\
\text { Female }\end{array}$ & $\begin{array}{c}\text { Difference } \\
\text { Score }\end{array}$ & $\begin{array}{c}\text { Preference } \\
\text { Ratio }\end{array}$ \\
\hline Sexually Experienced & 16 & 78.6 & 42.4 & $+36.2^{* *}$ & $14 / 2$ \\
Naive-Copulators & 15 & 24.3 & 10.2 & $+14.1^{*}$ & $12 / 3$ \\
Naive-Noncopulators & 10 & 9.4 & 5.6 & +3.8 & $6 / 4$ & \\
\hline
\end{tabular}

Note-Preference ratio is defined as the number of males preferring the receptive female divided by the number preferring the nonreceptive female. $\quad * p<.02 \quad * * 0<.01$ 
amount of time spent investigating each type of female separately. The three groups differed reliably in the amount of time spent investigating receptive females, Kruskal-Wallis one-way analysis of variance, $H(2)=14.1, p<.001$, and in the amount of time spent investigating nonreceptive females, $\mathrm{H}(2)$ $=15.7, \mathrm{p}<.001$. Moreover, the experienced males spent significantly more time investigating receptive females, Mann-Whitney $U$ tests, $p<.02$, and nonreceptive females $(p<.002)$ than did either of the two groups of naive males. The two groups of naive males did not differ significantly in the amount of time spent investigating receptive females or in the amount of time spent investigating nonreceptive females. These findings suggest that experienced males are more responsive than naive males to the composite bodily cues from females in general; i.e., without regard to their ovarian hormonal condition.

\section{EXPERIMENT 2}

The results of Experiment 1 show that heterosexually naive males which later prove to be copulators prefer receptive over nonreceptive anesthetized females, thus raising the question: which cue(s) mediate the preference? Observations by Calhoun (1962, pp. 152-158) on the mating pattern of wild Norway rats living in a seminatural environment suggest that olfaction plays a role in the rapprochement of the sex partners. Therefore, Experiment 2 was performed to determine whether naive male rats prefer the odor from receptive over nonreceptive females.

The technique used in this experiment was similar to that developed by Carr et al. (1965), but with certain changes being made to render the technique more like that used by other investigators who have reported that sexually naive male rats prefer the odor from receptive over nonreceptive females. We tested males aged 4.3 months, because those reporting such a preference used younger males (4-7 months) and those failing to find the preference used older males (7-15 months). Further, the test odors were collected from intact females in their natural receptive or nonreceptive state (LeMagnen, 1952), and the male subjects were housed in a room containing naturally cycling females (Pranzarone, 1968).

In addition, we used two control procedures not used by previous investigators reporting that naive males prefer the odor from receptive over nonreceptive females. First, we tested the males for sexual vigor after the odor preference test was completed, because the results of Experiment 1 showed that only those naive males which later prove to be copulators prefer receptive over nonreceptive anesthetized females. Second, when collecting odors from receptive and nonreceptive females, we excluded those which were in proestrus. Calhoun (1962, pp. 152-158) reported that, among wild rats living in a seminatural environment, females increase their scent marking behavior and males become responsive to the marks the night before the females become fully receptive. Calhoun also reported that wild males are more responsive to urine and feces from a domestic female collected the day before estrus and on the day of estrus than to such materials collected on other days of the female's estrual cycle.

\section{Method}

Subjects. Twenty male rats of the Long-Evans strain (Perfection Breeders) were tested at 4.3 months of age for their reactions to the odors from two females, one receptive and one nonreceptive. Beginning 1 month before testing, the males were maintained under the same conditions as in Experiment 1, except that they were housed two per cage.

Procedure and Apparatus. Each male subject was tested individually in its home cage for its reaction to two disposable cardboard containers. The test consisted of three 10 -min periods, each separated by $24 \mathrm{~h}$. One container had housed a receptive female for $1 \mathrm{~h}$ preceding the test, while the other had housed a nonreceptive female. Shortly before testing, the females were removed from the containers, leaving behind urine, feces, or other odorous materials. A line drawing of the test site and the disposable containers is shown elsewhere (Carr et al., 1965).

During the odor-preference test, an experimenter recorded the number of seconds the male spent investigating each of the two containers, located at opposite rear corners of the home cage. The cylindrical containers were made of heavy cardboard and measured $10.2 \times 17.8 \mathrm{~cm}$. Perforations in the cap at each end of a container allowed odor-laden air to pass into the cage, but the males could not see or touch the inner surfaces. A cardboard atrium measuring $10.2 \times 7.6 \mathrm{~cm}$ was attached to each container, and a male subject was said to be investigating a container if any part of its head extended inside the atrium. New containers and atria were used on each day of testing, and each male was presented with the odor from a given pair of females only once. The males and females were habituated to the containers by placing one of them in their home cages 4 days prior to testing.

Beginning 1 week after odor preference testing was completed, the male subjects were tested for sexual vigor. Each male was observed in its home cage with a receptive female for $20 \mathrm{~min}$ per day for 3 consecutive days. Males observed to ejaculate during at least one of these tests were designated as copulators, and 15 of the 20 males met the criterion.

The odor-preference tests were conducted using materials collected from 30 intact females of the same strain and age as the male subjects. They were maintained in the same manner as the males, except that the females were housed individually in wire mesh cages (Wahmann, LC-75/B). Beginning 10 days before testing, the females were given daily vaginal smears to establish their approximate ovarian cycle. On a given day of testing, those females judged to be receptive or nonreceptive were each placed with a sexually vigorous male, and odors were collected only from females exhibiting clear signs of receptivity or nonreceptivity. The lordotic reflex is a clear indication that the female is in estrus, and such females provided the receptive female odor. But the absence of the lordotic reflex does not preclude the female's being in proestrus, during which she may emit the sex attractant (Calhoun, 1962, pp. 152-158). Therefore, after their odors were collected and they were removed from the containers, the nonreceptive females were given an additional vaginal smear, and the containers which had housed females in proestrus were discarded. 
Table 2

Responses of Males to Receptive and Nonreceptive Female Odors During 30-Min Test

\begin{tabular}{|c|c|c|c|c|c|}
\hline \multirow[b]{2}{*}{$\begin{array}{c}\text { Naive Male } \\
\text { Subjects }\end{array}$} & \multicolumn{5}{|c|}{ Investigation Time (Seconds) } \\
\hline & $\mathrm{N}$ & $\begin{array}{c}\text { Receptive } \\
\text { Female Odor }\end{array}$ & $\begin{array}{l}\text { Nonreceptive } \\
\text { Female Odor }\end{array}$ & $\begin{array}{l}\text { Difference } \\
\text { Score }\end{array}$ & $\begin{array}{c}\text { Preference } \\
\text { Ratio }\end{array}$ \\
\hline $\begin{array}{l}\text { Copulators } \\
\text { Noncopulators }\end{array}$ & $\begin{array}{r}15 \\
5\end{array}$ & $\begin{array}{r}144.6 \\
95.9\end{array}$ & $\begin{array}{l}149.3 \\
108.2\end{array}$ & $\begin{array}{l}-4.7 \\
-12.3\end{array}$ & $\begin{array}{l}8 / 7 \\
2 / 3\end{array}$ \\
\hline
\end{tabular}

Note-Preference ratio is defined as the number of males preferring the receptive female odor divided by the number preferring the nonreceptive female odor.

\section{Results and Discussion}

Table 2 shows the performance during the 30 min odor-preference test of the two groups of heterosexually naive males; i.e., those which later proved to be copulators or noncopulators. Neither group of males showed a reliable preference for either type of female odor at the end of $30 \mathrm{~min}$ of testing, nor did they show a reliable preference at the end of 10 or $20 \mathrm{~min}$ of testing.

The present findings are consistent with several earlier reports that naive male rats show no reliable preference for the odors from receptive vs. nonreceptive females (Carr et al., 1965; Keesey, 1962; Lydell \& Doty, 1972; Nodine, 1959; Stern, 1970; Marasco, Note 2). However, other investigators have reported that naive males prefer the receptive over the nonreceptive female odor (LeMagnen, 1952; Pranzarone, 1968; Hitt, Phillips, \& Asato, Note 1). Therefore, we conclude that if naive male rats do, in fact, prefer the receptive female odor, the present testing conditions are not sufficiently sensitive to detect the preference, even though experienced males reliably prefer the receptive female odor under similar testing conditions (Carr et al., 1965, 1966, 1970).

\section{GENERAL DISCUSSION}

The investigation of the female's body is said to be an important component of the male rat's precopulatory pattern (Barnett, 1975, p. 138; Beach, 1956; Calhoun, 1962, pp. 152-158), and the results of Experiment 1 show that both heterosexually experienced and naive males which later prove to be copulators prefer receptive over nonreceptive anesthetized females. Such behavioral cues as vocalization, locomotion, or posturing (e.g., lordosis) were eliminated from the test. Therefore, the preference must be mediated by one or more bodily cues which distinguish receptive from nonreceptive females. Of the bodily cues which might mediate the preference (i.e., olfactory, gustatory, tactile, or visual), previous research has, thus far, implicated only olfactory cues. However, gustatory cues may also be important, since males frequently lick as well as sniff receptive females before mating. Moreover, wild Norway rats sometimes lick or eat the soil and other objects on which receptive females have deposited their scent (Calhoun, 1962, pp. 152-158).

Coupled with the findings from previous investigations conducted in this laboratory, the present findings lead us to conclude that heterosexual copulatory experience increases the responsiveness of male Norway rats to the bodily cue(s) serving as the female sex attractant. When provided with all of the bodily cues from receptive vs. nonreceptive females, both experienced males and naive males which later prove to be copulators reliably prefer receptive females (Experiment 1). However, when provided with only the odors from receptive vs. nonreceptive females, naive males which later prove to be copulators exhibit no reliable preference for either type of female odor (Experiment 2). Our conclusion that heterosexual copulatory experience increases the responsiveness of male rats to the bodily cue(s) serving as the female sex attractant is congruent with the conclusion drawn by Beach (1942), who showed that naive male rats require more stimulus-input from females to support their mating behavior than do. experienced males.

\section{REFERENCE NOTES}

1. Hitt, J. C., Phillips, I. T., \& Asato, H. Hormonal determinants of preference for female sex-odors in rats. Paper presented at the meeting of the Psychonomic Society. San Antonio, November 1970 .

2. Marasco, E. Responses of isolated naive male rats to sex odors. Unpublished manuscript, 1974. Available from Elizabeth Marasco, Department of Psychology, Princeton University, Princeton, New Jersey 08540.

\section{REFERENCES}

Barnett. S. A. The rat: $A$ study in behavior (rev. ed.). Chicago: University of Chicago Press, 1975.

BEACH, F. A. Analysis of the stimuli adequate to elicit mating behavior in the sexually inexperienced male rat. Journal of Comparative Psychology, 1942, 33, 163-207.

BEACH, F. A. Characteristics of the masculine "sex drive". In M. R. Jones (Ed.), Nebraska Symposium on Motivation (Vol. 4). Lincoln: University of Nebraska Press, 1956.

Bronson, F. H. Pheromonal influences on reproductive activities in rodents. In M. C. Birch (Ed.), Pheromones. Amsterdam: North-Holland, 1974.

CALHoun, J. B. The ecology and sociology of the Norway rat. (U.S. Public Health Service Publication No. 1008). Washington, D.C: U.S. Government Printing Office, 1962. 
CARR, W. J. Pheromonal sex attractants in the Norway rat. In L. Krames, P. Pliner, \& T. Alloway (Eds.), Advances in the study of communication and affect (Vol. 1). Nonverbal communication. New York: Plenum Press, 1974.

CARR, W. J., Loeb, L. S., \& Dissinger, M. L. Responses of rats to sex odors. Journal of Comparative and Physiological Psychology. 1965, 59, 370-377.

CARR, W. J., Loeb, L. S., \& Wylie, N. R. Responses to feminine odors in normal and castrated male rats. Journal of Comparative and Physiological Psychology, 1966, 62, 336-338.

Carr, W. J., Wylie, N. R., \& Loer, L. S. Responses of adult and immature rats to sex odors. Journal of Comparative and Physiological Psychology, 1970, 72, 51-59.

Gibson, J. J. The senses considered as perceptual systems. New York: Houghton Mifflin, 1966.

KEESEY, J. C. Olfactory preferences by heterosexually naive and experienced male rats for estrus and diestrus female urine. Unpublished master's thesis, San Jose State College, 1962.

LANDAUER, M. R. Sexual and olfactory preferences of male hamsters (Mesocricetus auratus Waterhouse) for conspecifics in different hormonal conditions. (Doctoral dissertation, University of Illinois at Urbana-Champaign, 1975). Dissertation Abstracts Intermational, 1975, 36, 2106B-2107B. (University Microfilms No. 75-24, 349).

Landuaer, M. R., Banks, E. M., \& Carter, C. S. Sexual and olfactory preferences of naive and experienced male hamsters (Mesocricetus auratus). Animal Behaviour, in press. (a)

Landauer, M. R., Banks, E. M., \& CARTier, C. S. Sexual preferences of male hamsters (Mesocricetus auratus) for conspecifics in different endocrine conditions. Hormones and Behavior, in press. (b)

LARsson, K. Conditioning and sexual behavior in the male albino rat. Stockholm: Almquist \& Wiksell, 1956.
Le Magnen, J. Les phenomenes olfacto-sexuels chez le rat blanc. Archives des Sciences Physiologiques, 1952, 6, 295-332.

LydELL, K., \& Doty, R. L. Male rat odor preferences for female urine as a function of sexual experience, urine age, and urine source. Hormones and Behavior, 1972, 3, 205.212.

McCall, R. B., Lester, M. L., \& Corter, C. M. Caretaker effect in rats. Developmental Psychology. 1969. 1, 771.

NoDine, C. The effects of non-exposure to post-partum estrous odor at a critical period in infancy upon adult mating behavior in the rat. Unpublished master's thesis. Bucknell University. 1959.

Pfaff, D.. \& Pfaffmann, C. Behavioral and electrophysiological responses of male rats to female rat urine odors. In C. Pfaffmann (Ed.). Ollaction and taste. Proceedings of the Third International Symposium. New York: Rockefeller University Press, 1969.

Pottier, J. J. G. . \& Baran. D. A general behavioral syndrome associated with persistent failure to mate in the male laboratory rat. Journal of Compurative and Physiological Psychology. 1973, 83. 499-509.

Pranzarone, G. F. The effects of differential exposure of male rats to estrous and diestrous female odors upon approach behavior and physiological development. Unpublished master's thesis. George Peabody College for Teachers, 1968.

STERN, J. J. Responses of male rats to sex odors. Physiology and Behavior, 1970, 5, 519-525.

WhALEN, R. E. Hormone-induced changes in the organization of sexual behavior in the male rat. Joumal of Comparative and Physiological Psychology, 1964, 57, 175-182.

WHALEN, R. E. Estrogen-progesterone induction of mating in female rats. Hormones and Behavior, 1974, 5, 157-162.

(Received for publication March 29, 1977; revision accepted June 14,1977 .) 